\title{
REVISÃO DO GÊNERO POTNIA STÅL (HOMOPTERA, MEMBRACIDAE, MEMBRACINAE, HOPLOPHORIONINI) ${ }^{1}$
}

\author{
Antônio J. Creão-Duarte ${ }^{2}$ \\ Albino M. Sakakibara ${ }^{3}$
}

\begin{abstract}
Revision of the genus Potnia Stál (Homoptera, Membracidae, MEMBRACINAE, HoplophorIONINI). Fifteen species of Potnia Stål, 1866 are presented with descriptions, illustrations and a key for identification. The following nomenclatural changes are introduced: $P$. knightae sp.n. (from Guiana), $P$. miracyae sp.n. (from Costa Rica), $P$. diringshofeni sp.n. (from Brasil), $P$. webbi sp.n. (from Brazil), $P$. turrialbensis sp.n. (from Costa Rica), P. pinheiroi sp.n. (from Brazil), P. tapuruquarensis sp.n. (from Brasil), $P$. cornigera sp.n. (from Brazil) and $P$. inca sp.n. (from Peru). Potnia venosa (Germar, 1821) = Aconophora nigrivittata Walker, 1851, syn.n. $=$ Potnia perobtusa Fowler, 1894, syn.n.. Potnia brevicornis Fowler, 1894, sp. reval. $=$ Potnia brunneifrontis Funkhouser, 1943, syn.n. $=$ Potnia maculata Funkhouser, 1943, syn.n.. Potnia jacula (Fabricius, 1803) = Potnia orthosoma Fonseca \& Diringshofen, 1974, syn.n.

KEY WORDS. Homoptera, Membracidae, Hoplophorionini, Potnia, taxonomy
\end{abstract}

STÅL (1866) criou o gênero Potnia onde acomodou Umbonia venosa (Germar, 1821) e Umbonia indicator Fairmaire, 1846. Definiu o gênero como tendo o tórax convexo, com ápice acuminado e ultrapassando o abdome; corno anterior comprimido, alongado; ângulos laterais pouco pronunciados.

METCALF \& WADE (1965) catalogaram dez espécies, todas da Região Neotropical (da América Central à Argentina).

MCKAMEY \& DEITZ (1996) revisaram a tribo Hoplophorionini a nível de gênero, acrescentando novos dados sobre a biologia de algumas espécies e também um estudo cladístico do grupo.

Neste presente estudo de Potnia são descritas 15 espécies, das quais nove são apresentadas como novas e uma revalidada.

Agradecemos às seguintes instituições que enviaram material por empréstimo: (AMNH) American Museum of Natural History, Estados Unidos; (BMNH) Natural History Museum, Inglaterra; (DZUP) Departamento de Zoologia, Universidade Federal do Paraná, Brasil; (INBIO) Instituto Nacional de Biodiversidad, Costa Rica; (MPEG) Museu Paraense Emílio Goeldi, Brasil; (MZSP) Museu de Zoologia, Universidade de São Paulo, Brasil; (NCSU) North Carolina State University, Estados Unidos; (NHRS) Naturhistoriska Ricksmuseet, Suécia; (ZMUH) Zoologisches Museum, Universität Hamburg, Alemanha.

1) Contribuição número 951 do Departamento de Zoologia, Universidade Federal do Paraná.

2) Departamento de Sistemática e Ecologia, Universidade Federal da Paraiba. 58059-900 João Pessoa, Paraíba, Brasil.

3) Departamento de Zoologia, Universidade Federal do Paraná. Caixa Postal 19020, 81531-990 Curitiba, Paraná, Brasil. Bolsista do CNPq. 


\section{Potnia Stål, 1866}

Potnia Stål, 1866: 388 (Espécie-tipo: Membracis venosa Germar, 1821; desig. subseq. Funkhouser, 1927). - Funkhouser, 1927: 94. - Metcalf \& Wade, 1965: 578. - Deitz, 1975: 43. - McKamey \& Deitz, 1991: 194. - McKamey \& Deitz, 1996: 321.

Hoplophora (Enchotypa) Stål, 1869: 37 (Espécie-tipo: Hoplophora granadensis Fairmaire, 1846) (Monotipia). -Metcalf \& Wade, 1965: 579.

Aconophoroides Fowler, 1894b: 47 (Espécie-tipo: Thelia gladiator Walker, 1851 (Monotipia). - Metcalf \& Wade, 1965: 579 (syn.). - McKamey \& Deitz, 1991: 194. - McKamey \& Deitz, 1996: 321.

Descrição. Colorido geral variando de castanho-amarelado a castanho-escuro; algumas vezes com manchas escuras no metopídio; processo anterior concolorido ou contornado de preto, não raramente com mancha avermelhada no meio. Cabeça sub-triangular, estreita, aproximadamente da metade da distância entre os angulos umerais; margem superior largamente arqueada. Olhos globulares, em geral pouco salientes. Ocelos equidistantes entre si e dos olhos, ou ligeiramente aproximados, situados logo acima da linha imaginária que passa pelo centro dos olhos. Pós-clípeo sub-globoso, com duas intumescências laterais, adjacentes às margens dos lóbulos supra-antenais.

Pronoto grosseiramente pontuado, em geral com carenas laterais longitudinais, também sobre o processo anterior quando presente; processo anterior mais ou menos desenvolvido, voltado para frente e para cima; nos machos, de um modo geral, muito reduzido ou ausente. Metopídio amplo, com marcas musculares bem evidentes; em alguns casos formando um pré-metopídio projetado acima da base da cabeça. Carena mediana percurrente, bem marcada ao longo do processo posterior; este levemente tectiforme, acuminado, podendo ultrapassar o ápice das tegminas.

Tegminas corrugadas entre as veias; estas bem definidas; cinco células apicais alongadas e paralelas entre si; veia $\mathbf{S}$ bifurcada pouco antes do meio; transversa $\mathbf{s}$ presente, fechando a célula discoidal $\mathbf{S}_{2}$; esta estreita e tão longa quanto a largura das tegminas; $\mathbf{M}$ e $\mathbf{C u}$ separando-se na base, unidas no terço basal pela primeira $\mathbf{m}$-cu e próximo ao ápice do clavo pela segunda $\mathbf{m}$-cu formando a célula discoidal $\mathbf{M}_{3+4}$, quase tão longa quanto a primeira. Clavo com apenas uma veia anal. Asas hialinas, com quatro células apicais, a quarta a menor; transversas s-m e m-cu presentes. Lóbulo jugal mais longo que largo.

Pernas I e II com tíbias estreitas e carenadas lateralmente; tarsos muuito longos, com até dois terços do comprimento das tíbias. Coxas II com espinho basal dirigido para trás, voltado para baixo e repousando sobre a superfície interna do fêmur. Pernas III clavadas, com as fileiras I e II fundidas nos três quartos apicais e com setas cuculadas em fileira; tarsos III reduzidos, menores que a metade do comprimento dos tarsos I e II.

Abdome achatado ventralmente. Pigóforo das fêmeas globoso, com ligeira depressão ventral junto às valvas; ovipositor não alcançando o seu ápice. Pigóforo dos machos com lóbulos laterais bem definidos.

Comentários. MCKAMEY \& DEITZ (1991) publicaram algumas mudanças nomenclaturais dentro de Hoplophorionini. Em Potnia, colocaram Aconophoroides Fowler, 1894 e Microschema Stål, 1869 como sinônimos, o primeiro apenas reafirmando a sinonímia feita por METCALF \& WADE (1965). Comentaram também 
que examinaram dois prováveis síntipos de Membracis venosa Germar, 1821, e que, decorrente dos estudos que vêm realizando dentro de Hoplophorionini, consideram diagnósticas as seguintes combinações de caracteres: cabeça estreita; pronoto estendendo posteriormente até próximo do ápice das tegminas em repouso; asas com transversa $r-m$ e com célula $R_{3}$ [a célula posterior à veia $R_{3}$ de DEITZ (1975)] mais longa que a célula $\mathrm{R}_{5}$; tíbias metatorácicas com setas cuculadas na fileira I (sensu DeITZ 1975). Acrescentaram ainda, que examinaram os tipos de Ochropepla dubia Fowler (antes colocada em Hoplophorion) e de Hoplophora straminicolor Stål (espécie-tipo de Microschema) e que concluiram ser congêneres a Potnia venosa.

SAKAKIBARA \& CREÃO-DUARTE (1996) constataram que houve um erro subsequente na etiquetagem do exemplar-tipo de Hoplophora straminicolor Stål, 1862, tendo este recebido uma etiqueta de "Alótipo" e , por outro lado, de "Holótipo" um exemplar que nem pertence à série-tipo. Com isso, Microschema Stål, 1869 (com a espécie-tipo Hoplophora straminicolor Stål, 1862) foi retirado da sinonímia de Potnia e revalidado.

\section{Chave para espécies de Potnia *}

*. Exceto para Potnia affinis Buckton cujo material não foi examinado.

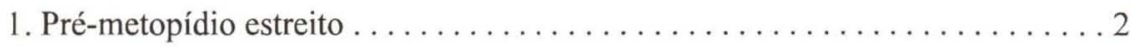

- Pré-metopídio largo, projetado para frente, sobrepondo a base da cabeça. (Só

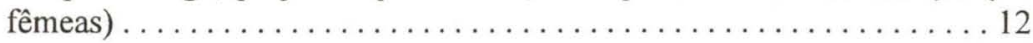

2. Processo anterior distintamente voltado para frente (somente fêmeas) . . . . 3

- Processo anterior voltado para frente e para cima ou ausente . . . . . . . . 4

3. Processo anterior ligeiramente comprimido e lateralmente carenado ...... jacula

- Processo anterior cônico, não carenado . . . . . . . . . . . . knightae sp.n.

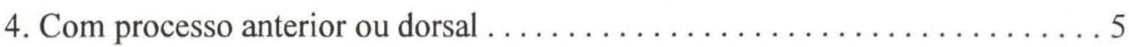

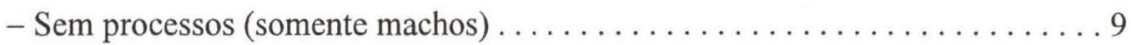

5. Com processo dorsal (situado acima dos ângulos umerais) . . . . . . . . 6

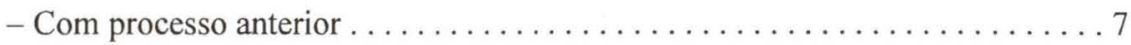

6. Processo dorsal vertical, mais ou menos comprimido lateralmente ..........

miracyae sp.n.

- Processo dorsal levemente inclinado para frente, sub-cônico. ....... rectispina

7. Processo anterior curto, representado por uma discreta projeção $\ldots \ldots \ldots \ldots \ldots$ diringshofeni sp.n.

- Processo anterior desenvolvido, duas vezes mais longo que largo . . . . . . 8

8. Edeago expandido lateralmente próximo ao ápice ........... webbi sp.n.

- Edeago não expandido lateralmente próximo ao ápice .... . turrialbensis sp.n.

9. Pronoto com a parte mais elevada angulosa $\ldots \ldots \ldots \ldots \ldots \ldots \ldots \ldots$

- Pronoto com a parte mais elevada arredondada . ................. 11 
10. Edeago com projeções laterais sub-apicais, declinadas para frente . ......... . pinheiroi sp.n.

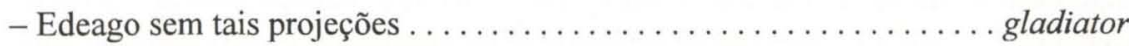
11. Superfície interna do edeago sem sinuosidades . . . . . . . . . . venosa - Superfície interna do edeago sinuosa ............. tapuruquarensis sp.n. 12. Processo anterior quase duas vezes mais longo que largo, com uma dilatação globosa próximo do ápice ................... cornigera sp.n.

- Processo anterior tão longo quanto largo, sem dilatação globosa . . . . . . 13 13. Processo anterior ligeiramente carenado . . . . . . . . . . brevicornis

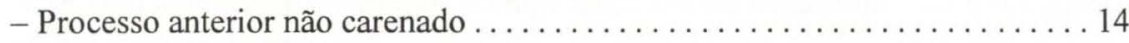
14. Metopídio com mancha escura em forma de $\mathrm{H} \ldots \ldots \ldots \ldots \ldots$ inca sp.n. - Metopídio com mancha escura transversal .............. granadensis

As espécies, descritas a seguir, estão na ordem de saída na chave.

\section{Potnia jacula (Fabricius, 1803)}

Figs $1-4,52$

Membracis jaculus Fabricius, 1803: 12 (Loc.-tipo: América Meridional).

Umbonia indicator Fairmaire, 1846: 279 (Loc.-tipo:Guiana Francesa, Cayenne).

Potnia indicator; Stål, 1866: 388. - McKamey \& Deitz, 1996: 323.

Potnia jaculus; Stål, 1869: 38. - Funkhouser, 1927: 95.

Potnia jacula; Dallas, 1870: 484. - Metcalf \& Wade, 1965: 582. - McKamey \& Deitz, 1996: 323.

Aconophoroides projecta Funkhouser, 1914: 405 (Loc.-tipo:Guiana, Bartica). - Funkhouser, 1927: 75.

- Metcalf \& Wade, 1965: 582 (syn.). - McKamey \& Deitz, 1996: 323.

Aconophoroides orthosoma Fonseca \& Diringshofen, 1974: 153 (Loc.-tipo: Brasil, Pará), syn.n.

Potnia orthosoma; McKamey \& Deitz, 1991: 194. - McKamey \& Deitz, 1996: 323.

Medidas (mm). fêmea/ macho. Comprimento do pronoto 13,83/11,38; comprimento do corpo 11,33/10,97; largura da cabeça 3,25/3,14; distância entre os ângulos umerais 5,42/5,24.

Caracteres diagnósticos. Pronoto carenado lateralmente, ligeiramente convexo na altura dos ângulos umerais; processo anterior reto, voltado para frente, concolorido, com três carenas, a mediana alcançando o ápice.

Descrição. fêmea. Colorido geral acastanhado, brilhante. Cabeça estreita.

Pronoto com pontuação grosseira, ligeiramente convexo dorsalmente na altura dos ângulos umerais; com, pelo menos, cinco carenas laterais, mais ou menos definidas. Processo anterior reto, voltado para frente, sem manchas nos bordos; com três carenas, a mediana alcançando o ápice. Metopídio amplo, com impressões musculares salientes. Processo posterior acuminado, alcançando o ápice das tegminas.

Macho. Menor, com processo anterior curto, projetado para frente, com ápice ligeiramente voltado para baixo. 


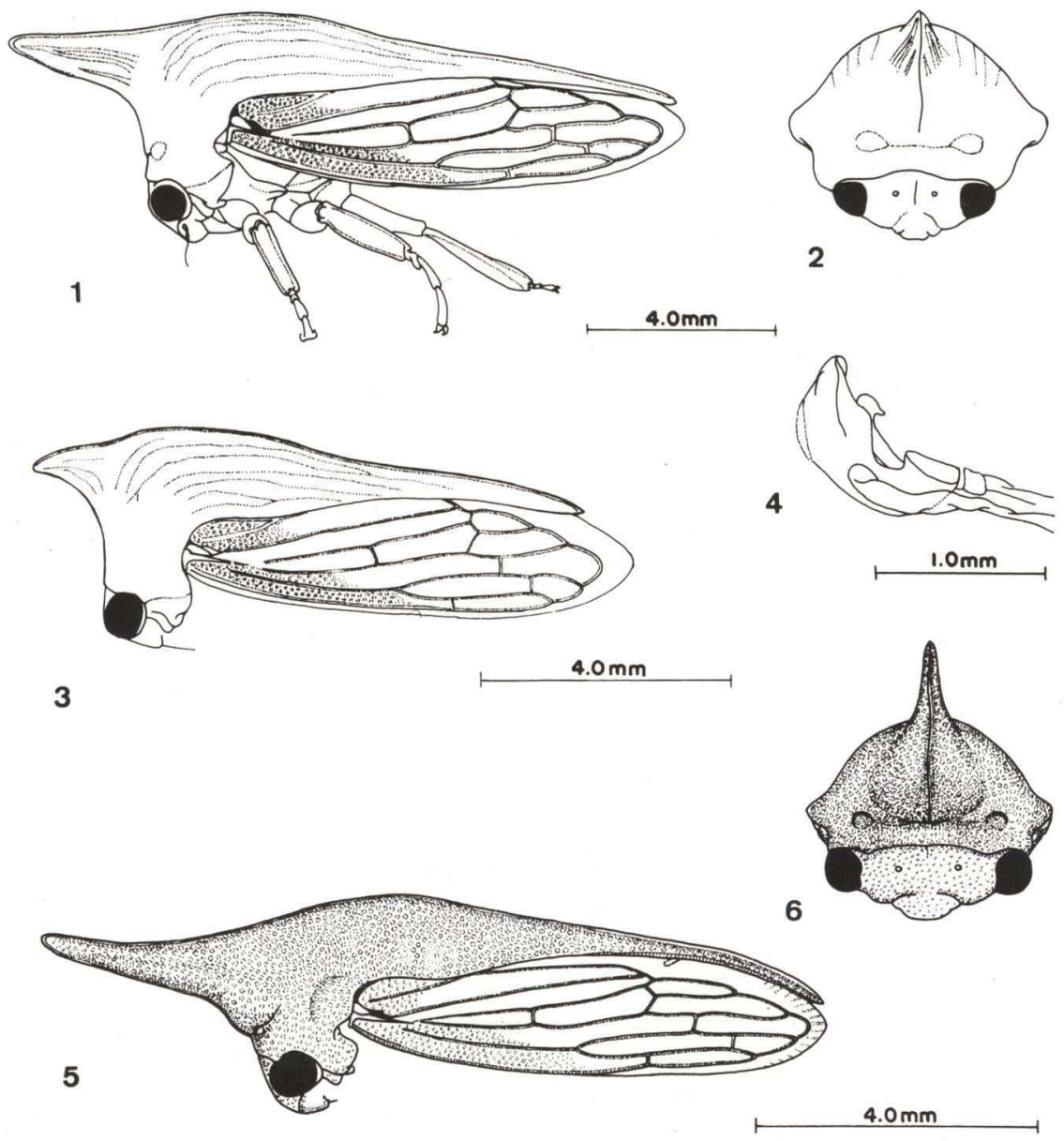

Figs 1-6. (1-4) Potnia jacula (Fabricius, 1803). (1-2) Fêmea; (3-4) macho. (5-6) Potnia knightae sp.n., fêmea.

Material examinado (só localidades). GUIANA, Essequibo; BRAsIL, Pará: Belém, Óbidos. (BMNH, MZSP).

Membracis jaculus Fabricius, 1803, (NHRS), apenas a foto foi examinada. Parátipo de Aconophoroides orthosoma Fonseca \& Diringshofen, 1974, (MZSP).

Comentários. A espécie aproxima-se de P. knightae sp.n., diferindo pelo processo anterior que é comprimido lateralmente e carenado. 


\section{Potnia knightae sp.n.}

Figs 5-6

Medidas (mm). fêmea. Comprimento do pronoto 11,33; comprimento do corpo 8,33; largura da cabeça 2,83; distância entre os ângulos umerais 3,50.

Caracteres diagnósticos. Olhos globulares e salientes. Pronoto sem carenas laterais, ligeiramente convexo na altura dos ângulos umerais. Processo anterior cônico, voltado para frente.

Descrição. Holótipo fêmea. Colorido geral castanho-amarelado.

Cabeça estreita, acentuadamente defletida. Olhos globulares e muito salientes. Pós-clípeo com uma carena transversal próxima da base, em arco.

Pronoto pontuado, sem carenas laterais, ligeiramente convexo dorsalmente na altura dos ângulos umerais; processo anterior cônico, bem desenvolvido, tão longo quanto a distância entre os ângulos umerais, voltado para frente. Metopídio amplo, sem manchas. Processo posterior acuminado, atingindo o ápice das tegminas.

Macho. Desconhecido.

Material examinado. Holótipo fêmea. GuIANA: "Confluence of the rivers Orenoco and New (650 ft.)". 16.X.1937. (BMNH).

Comentários. A espécie aproxima-se de $P$. jacula diferindo pelo seu tamanho menor, menos robusto; olhos muito projetados; pronoto sem carena laterais; processo anterior mais longo, cônico, não carenado.

Etimologia. Espécie dedicada a Dra. Janet Margerison-Knight (BMNH).

\section{Potnia miracyae sp.n.}

Figs $7-9$

Medidas (mm). fềmea. Comprimento do pronoto 7,25; comprimento do corpo 8,25; largura da cabeça 2,24; distância entre os ângulos umerais 3,72.

Caracteres diagnósticos. Pronoto levemente carenado. Processo dorsal desenvolvido, cônico, acuminado, carenado, alaranjado, com bordos negros. Tegminas ligeiramente escurecidas.

Descrição. Holótipo fêmea. Colorido geral amarelo-esverdeado. Processo dorsal alaranjado, com bordos negros. Tegminas ligeiramente escurecidas, com veias pretas. Abdome amarelado.

Cabeça estreita, com carena média evidente.

Pronoto com quatro carenas laterais discretas. Processo dorsal bem desenvolvido, em vista lateral triangular, quase tão largo na base quanto alto, acuminado, carenado, voltado para cima. Processo posterior acuminado, não alcançando o ápice das tegminas.

Macho. Desconhecido.

Material examinado. Holótipo fêmea. CosTA RICA, Puntarenas: Res. Bio. Monteverde/Est. La Casona (1.500m), VII.1991, N. Obando. (INBIO). 

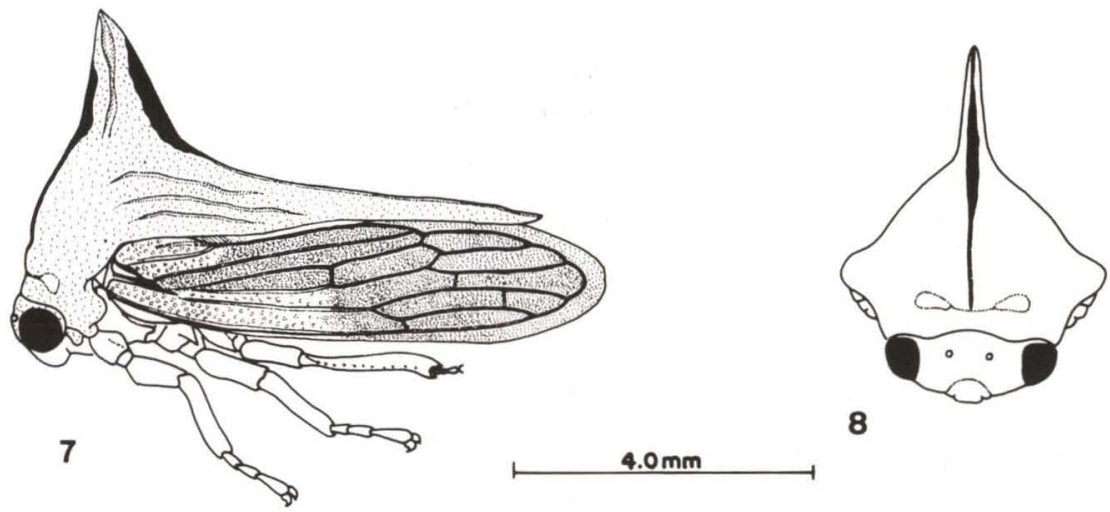

8
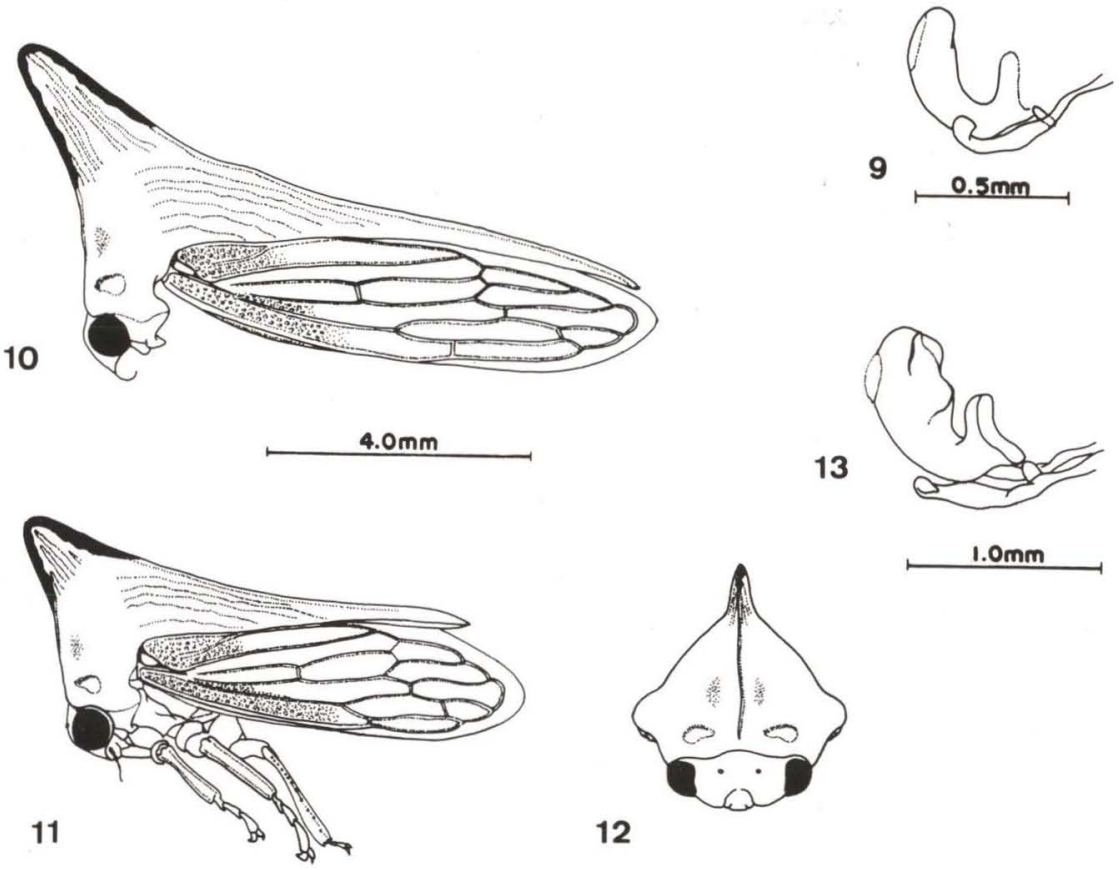

13

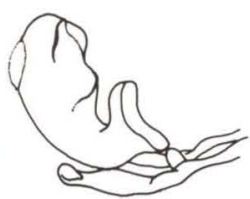

12
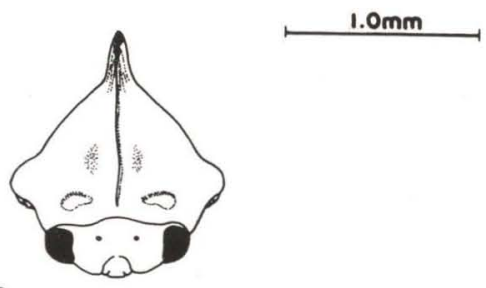

Figs 7-13. (7-9) Potnia miracyae sp.n., macho. (10-13) Potnia diringshofenisp.n.. (10) Fêmea; (11-13) macho.

Comentários. Esta espécie se aproxima de $P$. rectispina pelo metopídio discretamente convexo e pelo processo dorsal tendo os bordos escurecidos; a sua base entretanto, é muito larga.

Etimologia: espécie dedicada à Professora Miracy Garcia Rodrigues, da Faculdade de Ciências Agrárias do Pará. 


\section{Potnia rectispina (Funkhouser, 1914)}

Aconophoroides rectispina Funkhouser, 1914: 404 (Loc.-tipo: Bolívia). - Funkhouser, 1927: 75.

Potnia rectispina; Goding, 1929: 172. - Metcalf \& Wade, 1965: 583. - McKamey \& Deitz, 1996: 323.

Medidas (mm). fêmea. Comprimento do pronoto 8,80; comprimento do corpo 9,60; largura da cabeça 2,44; distância entre os ângulos umerais 4,60.

Caracteres diagnósticos. Pronoto sem carenas laterais; processo dorsal subcônico, inclinado para frente, enegrecido na base e com ápice amarelo.

Descrição. fêmea. Colorido geral castanho-amarelado; processo dorsal enegrecido nos dois terços basais, ápice amarelo.

Pronoto grosseiramente pontuado, sem carenas laterais; processo dorsal reto, inclinado para frente, sub-cônico, aproximadamente duas vezes mais longo que a sua largura basal. Processo posterior terminando na altura do ápice da quarta célula apical.

Macho. Desconhecido.

Material examinado (só localidade). Bolívia (USNM).

Holótipo fêmea de Aconophoroides rectispina Funkhouser, 1914. (USNM).

Comentários. Esta espécie é parecida com $P$. miracyae diferindo na forma do processo dorsal que é bem mais estreito na base, sub-cônico, e inclinado para frente. Não possui carenas laterais.

\section{Potnia diringshofeni sp.n. \\ Figs 10-13}

Medidas (mm). fêmea/ macho. Comprimento do pronoto 9,50/6,83; comprimento do corpo 8,17/6,83; largura da cabeça 2,33/2,00; distância entre os ângulos umerais $3,67 / 3,08$.

Caracteres diagnósticos. Pronoto com carenas laterais. Processo anterior curto, ligeiramente voltado para cima, com quatro carenas, bordos escuros tendo no centro uma área alaranjada. Metopídio com duas pequenas manchas escuras, próximas à carena mediana.

Descrição. Holótipo macho. Colorido geral acastanhado, brilhante; processo anterior com bordos escuros e no centro uma área alaranjada; metopídio com duas pequenas manchas escuras próximas à carena média.

Cabeça estreita, ligeiramente pontuada e pilosa.

Pronoto pontuado, com carenas laterais; processo anterior curto, dirigido para frente, ligeiramente voltado para cima, com quatro carenas. Processo posterior acuminado, alcançando o ápice da quinta célula apical das tegminas.

Fêmea. Maior, com processo anterior bem desenvolvido. Pigóforo tubuliforme, com as valvas não alcançando o seu ápice.

Material examinado. Holótipo macho. BRAsil, São Paulo: São Paulo, VII.1936. D. Braz. Parátipos: 4 fêmeas e 6 machos, com os mesmos dados do holótipo; 1 fêmea, ibidem II. 1928; 2 fêmeas, 2 machos, ibidem, V.1937, E. Schw.; 5 fêmeas, 6 machos, São Paulo/Jabaquara, H. Hamb.; 1 fêmea, ibidem, II.1948, Margarida; 5 fềmeas, 5 machos, São Paulo/Serra Negra, V.1950, D. Braz; 1 fêmea, 
4 machos, São Paulo/Bertioga, 1943; 2 fềmeas, 2 machos, São Paulo/Cidade Nova, V.1937, E. Schw.; 1 fêmea, São Paulo/Estação Biológica, 1942; 1 macho, São Paulo/Astrapera, VII.1937, E. Schw.; 1 macho, São Paulo, 31,X.1936, Zellibor Hauff. DZUP.

Série-tipo depositada no MZSP, exceto 4 parátipos:2 fêmeas e 2 machos no

Comentários. A espécie aproxima-se de P. webbi e P. turrialbensis, diferindo pelo processo anterior dos machos mais curto. A fêmea com processo anterior bem mais desenvolvido.

Etimologia. Espécie dedicada a Ricardo von Diringshofen (in memoriam).

\section{Potnia webbi sp.n.}

Figs 14-17

Medidas (mm). macho. Comprimento do pronoto 9,83; comprimento do corpo 8,33; largura da cabeça 2,05; distância entre os ângulos umerais 4,00.

Caracteres diagnósticos. Pronoto pontuado, com carenas laterais bem definidas. Processo anterior bem desenvolvido, voltado para frente e para cima, com os bordos escuros tendo, no centro, uma área avermelhada, com quatro carenas. Edeago com expansões laterais sub-apicais, com espinhos diminutos.

Descrição. Holótipo macho. Colorido geral castanho-escuro; processo anterior com bordos escuros e avermelhado no centro.

Pronoto pontuado, com carenas laterais bem definidas. Processo anterior bem desenvolvido, voltado para frente e acentuadamente para cima, com quatro carenas lateralmente. Metopídio sem manchas. Processo posterior acuminado, quase atingindo o ápice das tegminas.

Edeago com expansões laterais sub-apicais.

Fêmea. Desconhecida.

Material examinado. Holótipo macho. BrasiL, Mato Grosso: Sinop, X.1979, M. Alvarenga leg. (DZUP). Parátipos: 1 macho, ibidem, X.1975, M. Alvarenga leg. (DZUP).

Comentários. A espécie aproxima-se de $P$. turrialbensis diferindo pelo processo anterior não sub-espatulado e um pouco mais voltado para cima. $O$ edeago apresenta projeções laterais próximas do ápice.

Etimologia. Espécie dedicada ao Dr. Mick Webb, do BMNH.

\section{Potnia turrialbensis sp.n.}

Figs $18-20$

Medidas (mm). macho. Comprimento do pronoto 8,00; comprimento do corpo 7,00; largura da cabeça 2,17; distância entre os ângulos umerais 3,33.

Caracteres diagnósticos. Pronoto pontuado, com carenas laterais. Processo anterior bem desenvolvido, sub-espatulado, voltado para frente e para cima, com os bordos escuros e no centro duas carenas avermelhadas. 

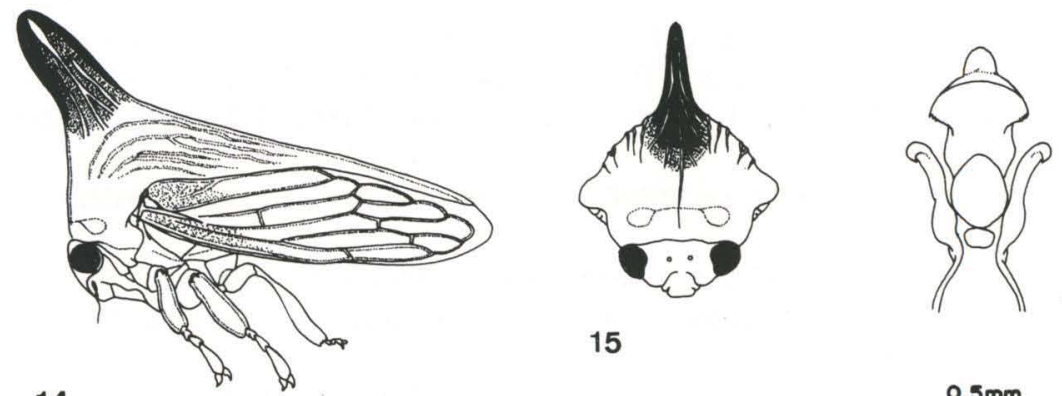

16

14

\section{5}

$4.0 \mathrm{~mm}$
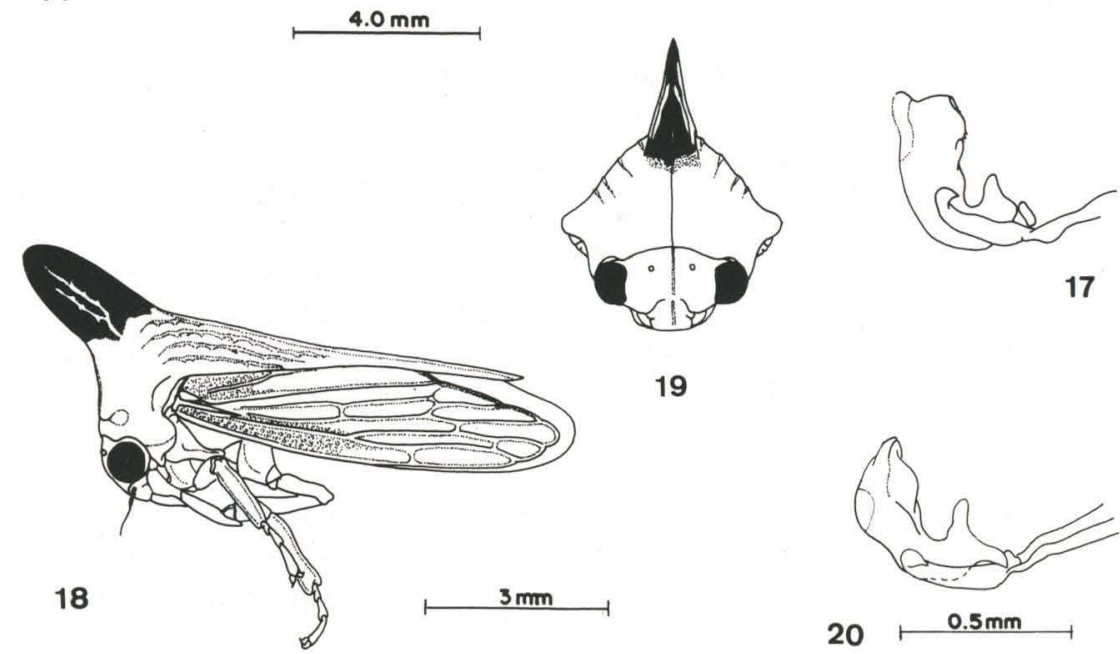

17

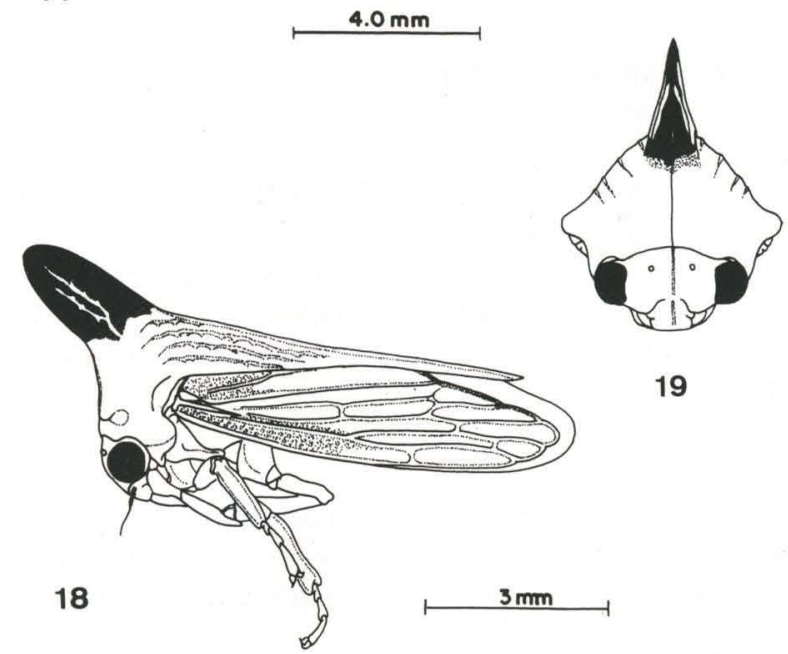

19
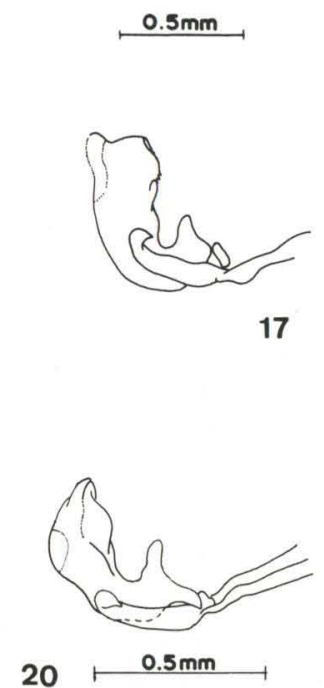

Figs 14-20. (14-17) Potnia webbi sp.n., macho. (18-20) Potnia turrialbensis sp.n., macho.

Descrição. Holótipo macho. Colorido geral castanho-escuro; processo anterior com os bordos escuros e com duas carenas avermelhadas; tegminas ligeiramente amareladas e veias acastanhadas.

Pronoto pontuado, com carenas laterais. Processo anterior bem desenvolvido, sub-espatulado, voltado para frente e para cima. Processo posterior acuminado, atingindo o ápice da quarta célula apical.

Edeago em U.

Fêmea. Desconhecida.

Material examinado. Holótipo macho. Costa RicA: Turrialba $(600 \mathrm{~m})$, 23.VI.1973, V.O. Becker leg. (DZUP). Parátipo: 1 macho, ibidem. Puntar/Golfo Dulce, $3 \mathrm{~km}$ SW, Rincón (10m), XII.1990, Hansen leg. (INBIO).

Comentários. A espécie é muito parecida com $P$. webbi diferindo pela coloração mais escura, o processo anterior sub-espatulado e pelas características do edeago.

Etimologia. O nome da espécie é alusivo à localidade-tipo. 


\section{Potnia pinheiroi sp.n.}

Figs 21-24

Medidas (mm). fêmea/ macho. Comprimento do pronoto 12,83//8,08; comprimento do corpo 10,50/7,92; largura da cabeça 3,00/2,42; distância entre os ângulos umerais 5,08/3,67.

Caracteres diagnósticos. Pronoto com carenas laterais bem definidas; em vista dorsal triangular; parte mais elevada angulosa, com duas carenas e mancha alaranjada circundada de escuro. Sem processo anterior.

Descrição. Holótipo macho. Colorido geral castanho-amarelado, brilhante; parte mais elevada do pronoto com uma mancha alaranjada circundada por uma outra escura.

Cabeça estreita, ligeiramente pontuada, pilosa, com carena média evidente. Pós-clípeo com duas carenas em T: a transversal logo abaixo da sutura epistomal, a vertical em prolongamento da carena média, indo quase até o limite com o anteclípeo.

Pronoto com carenas laterais bem definidas; em vista dorsal triangular, com a parte mais elevada angulosa, com duas carenas. Processo anterior ausente. Metopídio sem manchas. Processo posterior acuminado, ligeiramente voltado para baixo, com o ápice ultrapassando a extremidade da quarta célula apical, não alcançando porém a extremidade das tegminas.

Edeago em U, com projeções laterais subapicais, declinadas para frente.

Fêmea. Maior, com processo anterior longo, em forma de corno, dirigido para frente e para cima, com os bordos escuros, ao centro duas carenas alaranjadas, paralelas, atingindo o ápice. Processo posterior acuminado, indo além do ápice da terceira célula apical, não alcançando a extremidade das tegminas.

Material examinado. Holótipo macho. BrasiL, Mato Grosso: Sinop. X.1975, M. Alvarenga leg. Parátipos: 1 fêmea, com os mesmos dados do holótipo; 1 fêmea; Pará: Serra Norte, 20.X.1984. T. Pimentel leg.; 1 fêmea, ibidem, 17.VI.1985. R.D. Thomas leg.; 1 macho, ibidem, 17.IX.1985, M.F. Torres leg..

Holótipo e um parátipo fêmea depositados no DZUP. Os demais no MPEG.

Comentários. A espécie aproxima-se muito de $P$. gladiator diferindo apenas pela genitália do macho. As fềmeas são semelhantes.

Etimologia. Espécie dedicada ao professor Eurico Pinheiro, da Faculdade de Ciências Agrárias do Pará.

\section{Potnia gladiator (Walker, 1851)}

\section{Figs 25-28, 51}

Thelia gladiator Walker, 1851: 567 (Loc.tipo: Pará).

Aconophoroides gladiator; Fowler, 1894b: 48. - Funkhouser, 1927: 75.

Potnia gladiator; Goding, 1928: 211. - Metcalf \& Wade, 1965: 580. - McKamey \& Deitz, 1996: 323. Aconophora lata Walker, 1858: 69 (Loc.-tipo: ?). - Funkhouser, 1927: 75 (syn.). - Metcalf \& Wade, 1965: 580. - Broomfield, 1971: 357. - McKamey \& Deitz, 1996: 323.

Aconophora gigantea Butler, 1878: 352 (Loc.-tipo: Pará). - Funkhouser, 1927: 106. - Metcalf \& Wade, 1965: 580 (syn.). - Broomfield, 1971: 352. - McKamey \& Deitz, 1996: 323. 
Platycotis sicula Buckton, 1902: 100 (Loc.-tipo). - Funkhouser, 1927: 75. - Metcalf \& Wade, 1965: 581

(syn.). - McKamey \& Deitz, 1996: 323.

Medidas (mm). fêmea/macho. Comprimento do pronoto 11,83/7,17; comprimento do corpo 9,50/8,00; largura da cabeça 2,88/2,32; distância entre os ângulos umerais 4,25/4,16.

Caracteres diagnósticos. Tamanho grande. Colorido geral castanho-escuro. Pronoto com cinco carena laterais. Processo anterior bem desenvolvido, voltado para frente e para cima, com os bordos negros e duas carenas avermelhadas alcançando o ápice.

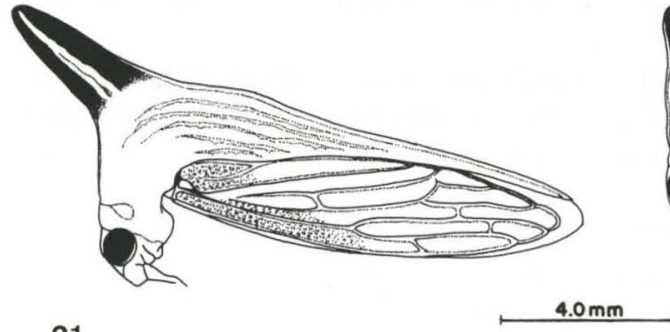

21

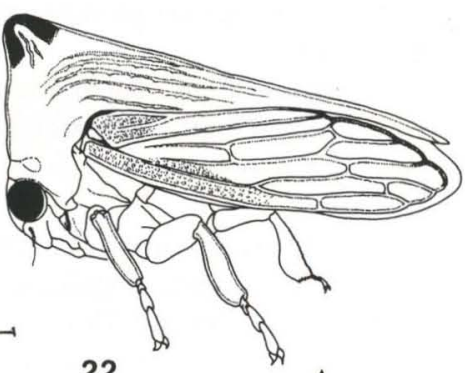

22

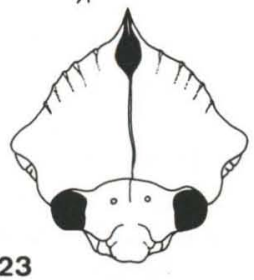

23

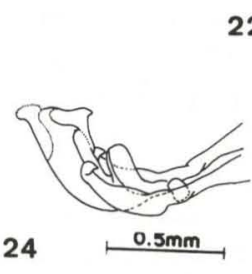

24

$0.5 \mathrm{~mm}$

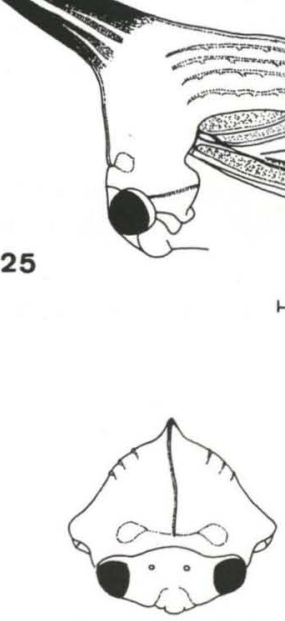

26
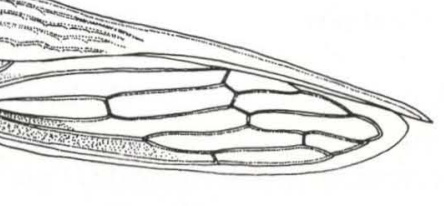

$4.0 \mathrm{~mm}$
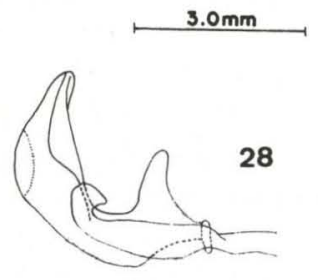

$1.0 \mathrm{~mm}$

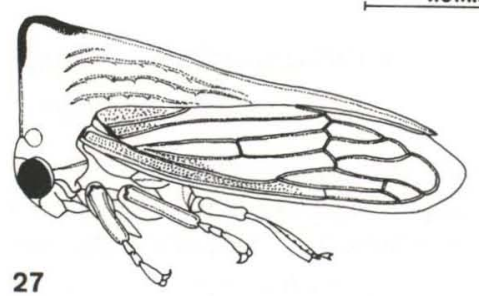

Figs 21-28. (21-24) Potnia pinheiroisp.n.. (21) Fêmea; (22-24) macho. (25-28) Potnia gladiator (Walker, 1851). (25) Fêmea; (26-28) macho. 
Descrição. fêmea. Colorido geral castanho-escuro; processo anterior com bordos negros e avermelhado medianamente sobre as carenas.

Cabeça estreita; carena média evidente.

Pronoto pontuado, com cinco carenas laterais distintas. Processo anterior bem desenvolvido, voltado para frente e para cima, com duas carenas alcançando o ápice. Processo posterior acuminado, ligeiramente voltado para baixo, com o ápice ultrapassando a extremidade das tegminas.

Macho. Menor, sem processo anterior. Parte mais elevada do pronoto avermelhada, com bordos escuros. Edeago em U, com ápice espatulado.

Material examinado (só localidades). BRASIL, Amazonas: Canuma; Manaus, Uypiranga. GuIANA, Bartica: Kartabo; Rio Maroni. (AMNH, BMNH, NCSU).

Thelia gladiator, A. lata e $A$. gigantea (BMNH), foram examinados apenas fotos.

Comentários. A espécie aproxima-se de $P$. pinheiroi, diferindo pelas estruturas da genitália do macho; o edeago não apresenta projeções próximas de seu ápice.

\section{Potnia venosa (Germar, 1821)}

Figs 29-33, 54

Membracis venosa Germar, 1821: 19 (Loc.-tipo: Brasil).

Hoplophora venosa; Germar, 1835: 241.

Umbonia venosa; Fairmaire, 1846: 278.

Aconophora nigrivittata Walker, 1851: 539 (Loc.-tipo: ?). - Broomfield, 1971: 364. syn.n.

Potnia venosa; Stål, 1866: 388. - Funkhouser, 1927: 94. - Metcalf \& Wade, 1965: 584. - McKamey \& Deitz, 1996: 323 (design. Lectótipo).

Potnia perobtusa Fowler, 1894a: 418 (Loc.tipo: Brasil, Rio de Janeiro). - Metcalf \& Wade, 1965: 583.

- McKamey \& Deitz, 1996: 323. syn.n.

Potnia jansoni Fowler, 1894a: 418 (Loc.tipo: Guiana, Demerara). - Metcalf \& Wade, 1965: 583 (= P. nigrivittata Walker) (error), syn.n.

Potnia nigrivittata; Metcalf \& Wade, 1965: 583. - McKamey \& Deitz, 1996: 323.

Potnia straminicolor; McKamey \& Deitz, 1991: 194 (nec Stål, 1862). - McKamey \& Deitz, 1996: 323 (nec Stål, 1862). - Sakakibara \& Creão-Duarte, 1996: 996.

Medidas (mm). fêmea/ macho. Comprimento do pronoto 9,75/5,58; comprimento do corpo 8,25/6,50; largura da cabeça 2,42/2,08; distância entre os ângulos umerais $3,67 / 3,25$.

Caracteres diagnósticos. Pronoto com carenas laterais, sem processo anterior ou dorsal; em vista dorsal, triangular com a parte mais elevada arredondada, com uma mancha alaranjada circundada por outra escura, projetando em direção aos úmeros. Metopídio com duas pequenas manchas escuras.

Descrição. macho. Colorido geral castanho, brilhante, com a parte mais elevada do pronoto com mancha alaranjada circundada por outra escura; metopídio com duas pequenas manchas escuras.

Cabeça estreita, ligeiramente pontuada, pilosa, com carena média distinta. Pós-clípeo com duas carenas formando um $\mathrm{T}$, a transversal logo abaixo da sutura epistomal, a vertical indo até quase o limite com o ante-clípeo. 

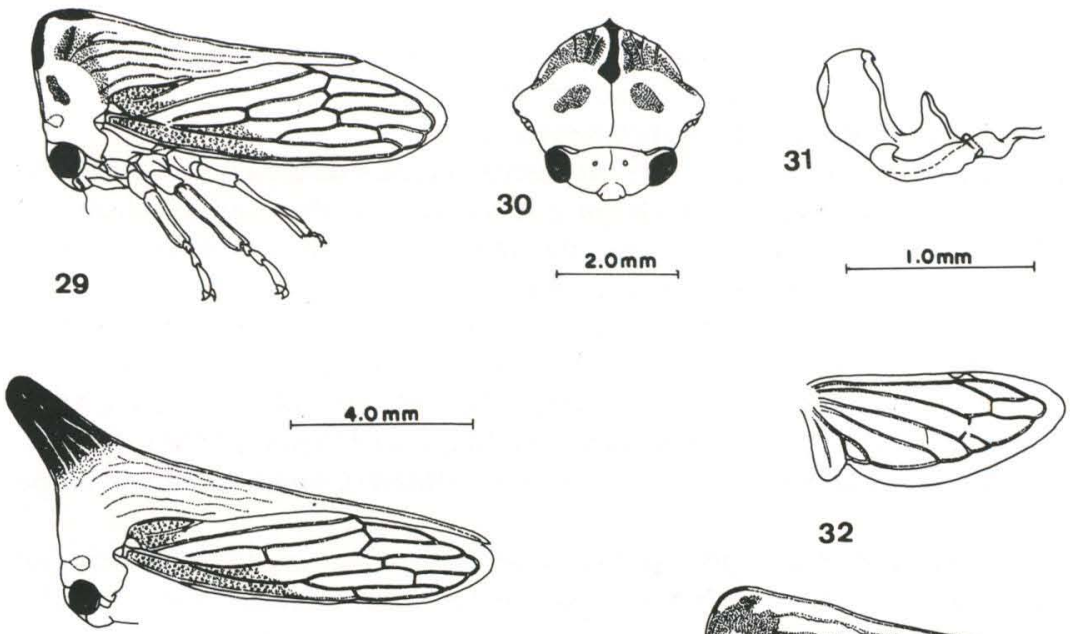

32

33
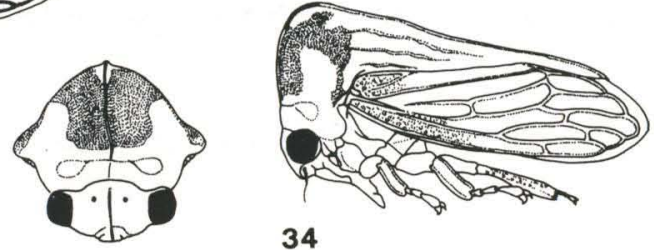

34

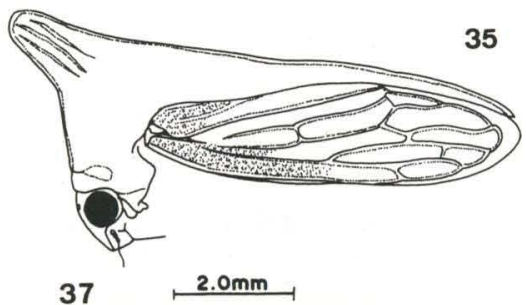

36

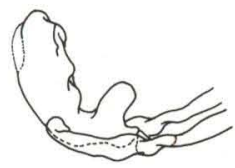

$\stackrel{0.5 \mathrm{~mm}}{\stackrel{2}{\longrightarrow}}$

Figs 29-37. (29-33) Potnia venosa (Germar, 1821). (29-32) Macho; (33) fêmea. (34-37) Potnia tapuruquarensis sp.n.. (34-36) Macho; (37) fêmea.

Pronoto pontuado, com carenas laterais; sem processos; em vista dorsal triangular, parte mais elevada arredondada. Processo posterior acuminado, não alcançando o ápice da quinta célula apical das tegminas.

Fêmea. Maior. Pronoto com quatro ou mais carenas laterais pouco definidas. Processo anterior em forma de corno, dirigido para frente e para cima, com os bordos escuros tendo ao centro três carenas. Processo posterior acuminado, atingindo o ápice das tegminas. Pigóforo tubuliforme, com as valvas não alcançando o seu ápice.

Material examinado (só localidades). BRASIL, Rio de Janeiro: Rio de Janeiro; Itatiaia; Pará: Óbidos; Itaituba. (MZSP, DZUP).

Paralectótipo fêmea de Aconophora nigrivittata Walker (BMNH).

Comentários. Pela descrição, Germar tinha em mãos um exemplar fêmea, a deduzir pela referência a um processo anterior em forma de corno ereto. MCKAMEY \& DEITZ (1991) examinaram dois exemplares que acreditaram ser síntipos de $M$. 
venosa (um pertencente a Martin-Luther Universität, Halle e outro ao Zoologisches Museum, Universität von Hamburg). Examinaram também, o exemplar-tipo de Hoplophora straminicolor Stål, 1862, chegando à conclusão de que se tratava de Potnia venosa. SAKAKIBARA \& CREÃo-DUARTE (1996) entretanto, constataram que a etiqueta de "Holótipo" fora colocada em um exemplar que não o tipo.

\section{Potnia tapuruquarensis sp.n.}

Figs 34-37

Medidas (mm). fêmea/ macho. Comprimento do pronoto 8,75/5,33; comprimento do corpo 7,67/6,08; largura da cabeça 2,42/2,00; Distância entre os ângulos umerais $3,67 / 3,08$.

Caracteres diagnósticos. Pronoto em vista dorsal, triangular, com carenas laterais. Processo anterior ausente. Metopídio com grande mancha escura projetada para cima até a parte mais elevada e em direção aos ângulos umerais.

Descrição. Holótipo macho. Colorido geral castanho, brilhante. Metopídio com uma grande mancha escura estendida para cima e para os ângulos umerais. Abdome acastanhado, brilhante.

Cabeça estreita, ligeiramente pontuada e pilosa. Pós-clípeo com duas carenas cruzando nas proximidades da sutura epistomal, a vertical em continuação ao vértice e a transversal saindo das intumescências laterais, adjacentes às margens internas dos lóbulos supra-antenais.

Pronoto em vista dorsal triangular, pontuado, com carenas laterais. Processo anterior ausente.

Edeago em U, com duas sinuosidades na superfície interna.

Fêmea. Maior; pronoto com carenas suaves, pouco definidas. Processo anterior em forma de corno, dirigido para frente e para cima, com os bordos claros, três ou quatro carenas. Processo posterior acuminado, atingindo o ápice das tegminas. Pigóforo tubuliforme, com as valvas não alcançando o seu ápice.

Material examinado. Holótipo macho. BRASIL, Amazonas: Tapuruquara, VII.1962, F.M. Oliveira leg. (DZUP). Parátipos: 3 fêmeas e 2 machos, com os mesmos dados do holótipo (DZUP).

Comentários. Esta espécie é parecida com $P$. venosa porém um pouco menor. Os machos diferem pela mancha no metopídio e pelos caracterres do edeago; as fêmeas pelo processo anterior com os bordos claros.

Etimologia. O nome da espécie é alusivo à localidade-tipo.

\section{Potnia cornigera sp.n.}

Figs $38-40$

Medidas (mm). fêmea. Comprimento do pronoto 5,50; comprimento do corpo 5,83; largura da cabeça 1,84; distância entre os ângulos umerais 2,96.

Caracteres diagnósticos. Processo anterior bem desenvolvido, duas vezes mais longo que largo, voltado para frente e para cima, com uma dilatação globosa perto do ápice. 


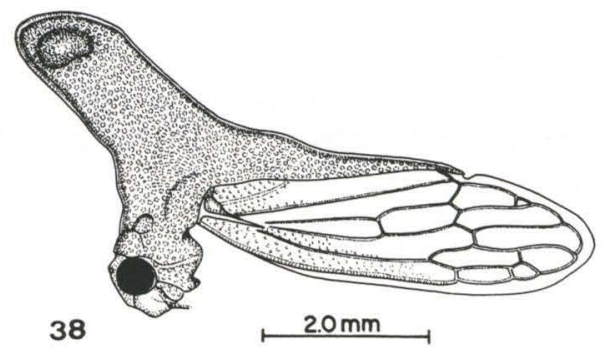

39

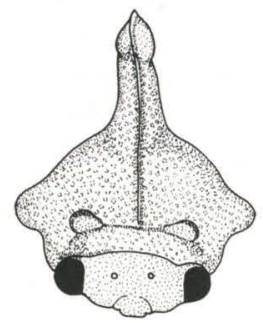

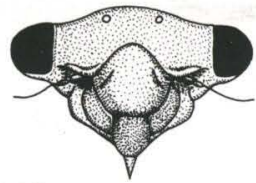

40

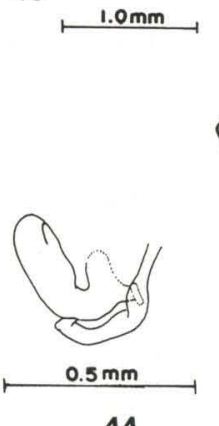

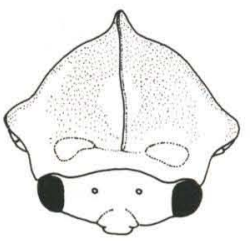

42

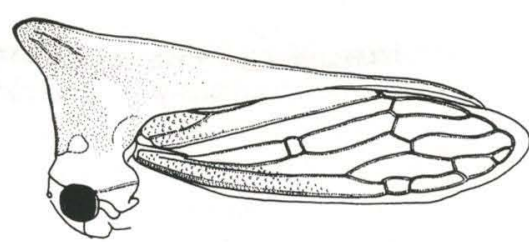

41

43

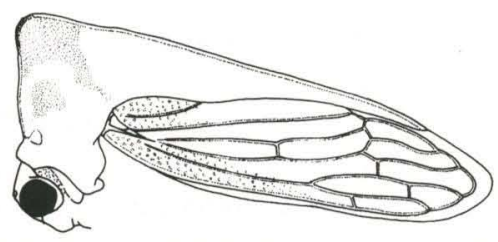

Figs 38-44. (38-40) Potnia cornigera sp.n., fêmea. (41-44) Potnia brevicornis (Fowler, 1894). (41-42) Fêmea; (43-44) macho.

Descrição. Holótipo fêmea. Colorido geral castanho-amarelado.

Pronoto com pontuação densa, sem carenas laterais. Processo anterior bem desenvolvido, duas vezes mais longo que largo, voltado para frente e para cima, com uma dilatação globosa perto do ápice. Metopídio sem manchas. Processo posterior acuminado, não alcançando a extremidade da quinta célula apical das tegminas.

Macho. Desconhecido.

Material examinado. Holótipo fêmea. Brasil, Paraná: Ponta Grossa, 30.X.1937, J.P. Machado leg. (DZUP).

Comentários. Pela ausência de setas cuculadas nas fileiras I e II das tíbias III, a espécie aproxima-se de $P$. granadensis e de $P$. inca, das quais difere pela ausência de manchas no metopídio.

Etimologia. O nome da espécie é alusivo ao processo anterior desenvolvido. 


\section{Potnia brevicornis (Fowler, 1894), sp. reval.}

Figs $41-44,53$

Potnia brevicornis Fowler, 1894b: 46 (Loc.-tipo: Panamá). - Funkhouser, 1927: 95. - Metcalf \& Wade, 1965: 581. - Broomfield, 1971: 337. - McKamey \& Deitz, 1996: 323 (= P. granadensis) (error). Potnia brunneifrontis Funkhouser, 1943: 464. - Metcalf \& Wade, 1965: 580.--McKamey \& Deitz, 1996: 323. syn.n.

Potnia maculata Funkhouser, 1943: 464. - Metcalf \& Wade, 1965: 583.-McKamey \& Deitz, 1996: 323. syn.n.

Medidas (mm). fêmea. Comprimento do pronoto 5,00; comprimento do corpo 4,55; largura da cabeça 1,67; distância entre os ângulos umerais 2,33.

Caracteres diagnósticos. Processo anterior curto, dirigido para frente, ligeiramente para cima, com duas pequenas carenas. Metopídio com mancha na metade superior, alcançando o ápice do processo anterior e os ângulos umerais.

Descrição. Lectótipo fêmea. Colorido geral castanho-amarelado; metopídio com mancha escura na metade superior estendendo até o ápice do processo anterior e os ângulos umerais.

Pronoto pontuado, sem carena laterais. Processo anterior curto, dirigido para frente e ligeiramente para cima, com duas pequenas carenas. Processo posterior acuminado, não indo além da quinta célula apical das tegminas.

Macho. Sem processo anterior; edeago em U, com espinhos diminutos sub-apicais, dispostos em semi-círculo na superfície interna.

Material examinado (só localidades). CosTA RiCA. Guanacaste/Est. Martiza, $600 \mathrm{~m}$ W Volcan Orosi; Puntarenas/P.N. Amistad/Estac. Las Melizas; Peninsula de Osa (200m); San Jose. Panamá. Volcan de Chiriqui (1.000-6.000 ft). Brasil, Pará: Mocajuba; Amapá: Serra do Navio. (BMNH, DZUP, INBIO, ZMUH).

Lectótipo fêmea de Potnia brevicornis Fowler (BMNH).

Comentários. METCALF \& WADE (1965) consideraram P. brevicornis como sinônimo de $P$. granadensis. O exame do lectótipo de $P$. brevicornis permitiu a sua revalidação.

\section{Potnia inca sp.n.}

Figs $45-46,50$

Medidas (mm). fêmea. Comprimento do pronoto 4,42; comprimento do corpo 5,67; largura da cabeça 1,24; distância entre os ângulos umerais 2,60.

Caracteres diagnósticos. Pronoto com discreta sinuosidade; sem carenas laterais. Metopídio com mancha em forma de $\mathrm{H}$.

Descrição. Holótipo fêmea. Colorido geral castanho-amarelado; metopídio com mancha escura; processo posterior escurecido no terço apical.

Pronoto grosseiramente pontuado, com discreta sinuosidade; sem carenas laterais. Processo anterior comprimido lateralmente, sub-espatulado, dirigido para frente e ligeiramente para cima, sem carenas. Processo posterior acuminado, não alcançando a extremidade da quinta célula apical das tegminas.

Macho. Desconhecido. 

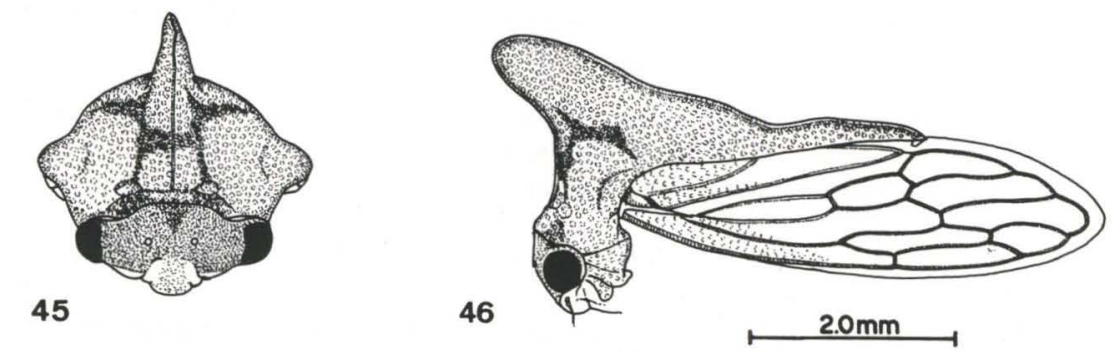

47
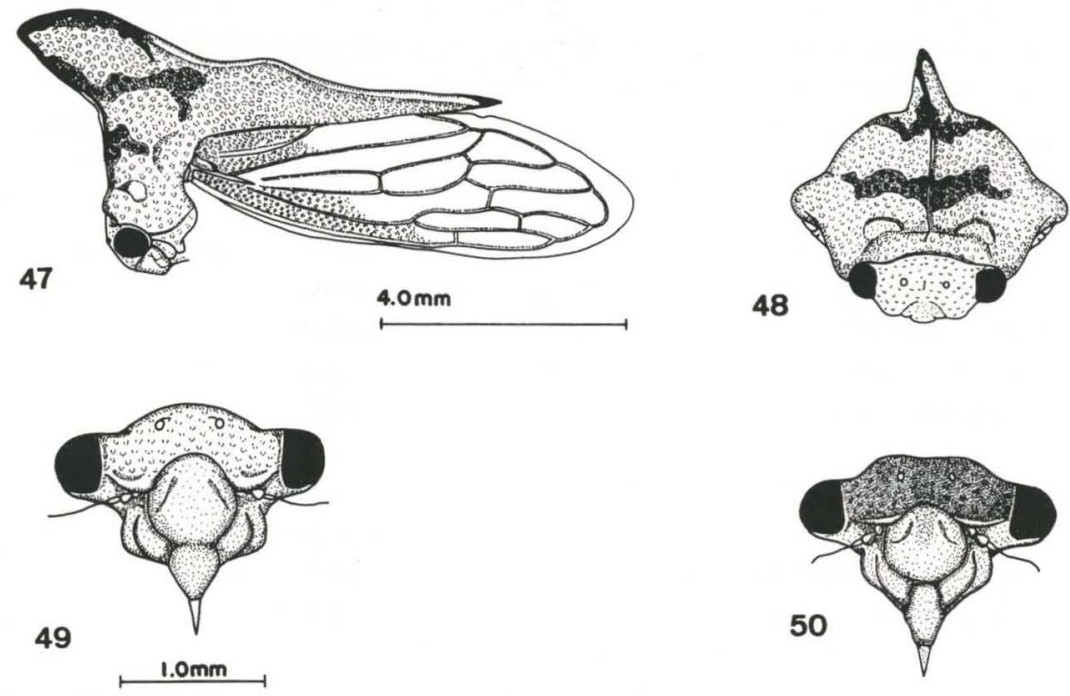

Figs 45-50. (45-46, 50) Potnia inca sp.n., fêmea. (47-49) Potnia granadensis (Fairmaire, 1846), fêmea.

Material examinado. Holótipo fêmea. PERU, Cajamarca: Banos del Inca/ Roadside shrubs (8000 ft), 27.VIII.1971, P.S. \& H.L. Broomfield (BMNH).

Comentários. A espécie aproxima-se de P. granadensis diferindo pelo tamanho menor e pela mancha no metopídio.

Etimologia. $\mathrm{O}$ nome da espécie é alusivo à antiga civilização do Peru.

\section{Potnia granadensis (Fairmaire, 1846)}

Figs $47-49$

Hoplophora granadensis Fairmaire, 1846: 273 (Loc.-tipo: Colômbia).

Potnia granadensis; Stål, 1869: 267. - Funkhouser, 1927: 95. - Metcalf \& Wade, 1965: 581.-McKamey \& Deitz, 1996: 323. 

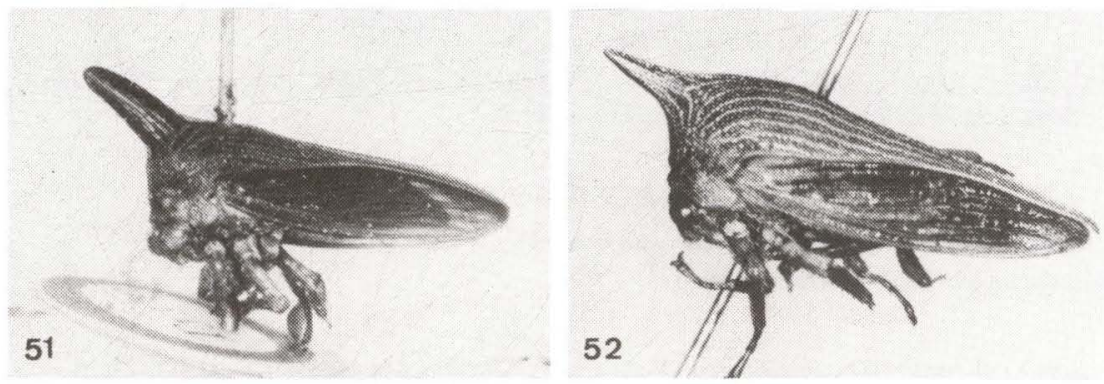

53
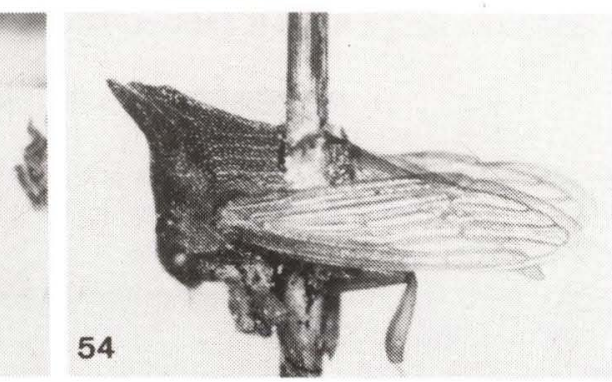

Figs 51-54. Fotos de tipos (a partir de slides). (51) Thelia gladiator Walker, 1851, holótipo fêmea; (52) Membracis jaculus Fabricius, 1803, holótipo; (53) Potnia brevicornis Fowler, 1894, lectótipo fêmea; (54) Aconophora nigrivittata Walker, 1851, lectótipo fêmea (= Potnia venosa).

Medidas (mm). fêmea. Comprimento do pronoto 6,42; comprimento do corpo 7,17; largura da cabeça 2,00; distância entre os ângulos umerais 3,67.

Caracteres diagnósticos. Pronoto com discreta elevação no meio, sem carenas laterais. Processo anterior desenvolvido, achatado lateralmente, sub-espatulado, voltado para frente e ligeiramente para cima, sem carenas; bordos levemente escurecidos. Metopídio com mancha escura transversal.

Descrição. Colorido geral castanho-amarelado; processo anterior com bordos escurecidos; escurecimento este estendendo-se para os ângulos umerais; metopídio com mancha transversa escura.

Pronoto com pontuação densa; em vista lateral com uma elevação no meio; sem carenas laterais. Processo anterior desenvolvido, voltado para frente e ligeiramente para cima, sub-espatulado, sem carenas. Processo posterior acuminado, ápice não alcançando a extremidade da quinta célula apical das tegminas.

Macho. Desconhecido.

Material examinado (só localidades). Costa RicA, Cache. BRAsil, Pará: Belém. (BMNH, MZSP).

Comentários. A espécie aproxima-se de $P$. inca diferindo pelas manchas no processo anterior e no metopídio. 


\section{ESPÉCIES NÃO EXAMINADAS}

\section{Potnia affinis Buckton, 1902}

Potnia affinis Buckton, 1902: 103 (Loc.-tipo: Colômbia, Bogotá). - Metcalf \& Wade, 1965: 580.McKamey \& Deitz, 1996: 323 (Design. Lectótipo).

\section{Potnia dubia (Fowler, 1894)}

Ochropepla dubia Fowler, 1894: 45 (Loc.-tipo: Panamá). - McKamey \& Deitz, 1991: 162.

Potnia dubia; McKamey \& Deitz, 1996: 323.

AGRADECIMENTOS. Em especial a C. Godoy, I. Gorayeb, J. Margerison-Knight, L.L. Deitz, S.H. McKamey, T.J. Henry, H. Strümpel e U.R.M. de Souza.

\section{REFERÊNCIAS BIBLIOGRÁFICAS}

BRoOMFIELD, P.S. 1971. A catalogue of the membracid types (Homoptera: Membracidae) in the British Museum (Natural History). Bull. British Museum (Nat. Hist.) Ent. 25 (8): 325-386.

BuckTon, G.B. 1902. A Monograph of the Membracidae. London, Lowell Reeve \& Co. Lmtd, 92p.

BUTLER, A.G. 1878. On various genera of the Homopterous family Membracidae, with descriptions of new species, and a new genus in the collection of the British Museum. Cist. Ent. 2: 337-361.

DALLAS, W.S. 1870. Rhynchota. Zool. Rec. 6: 482-499.

DeITZ, L.L. 1975. Classification of the higher categories of the New World treehoppers (Homoptera: Membracidae). North Carolina Agric. Exper. Stat. Tech. Bull. 225, Raleigh: 1-177.

FABRICIUS, J.C. 1803. Rhyngota. Systema Rhyyngotorum secundum ordines, genera, species, adiectis synonymis, locis, observationibus, descriptionibus. $101 \mathrm{p}$.

Fairmaire, L.M.H. 1846. Revue de la tribu des Membracides. Ann. Soc. Ent. Fr. 4 (2): 235-320.

FONSECA, J.P. DA \& R. VON DIRINGSHOFEN. 1974. Contribuição ao conhecimento dos Membracídeos Neotrópicos (Homoptera: Membracidae). VII. Arq. Inst. Biológico, São Paulo, 41 (4): 151-160.

Fowler, W.W. 1894a. Some new species of Membracidae. Trans. Entomol. Soc. London: 415-424.

1894b. Order Rhynchota: Suborder Hemiptera - Homoptera. Biol. Centr. Amer. 2: 1-173.

Funkhouser, W.D. 1914. New South American Membracidae. Can. Ent. 46: 403-408.

1927. Membracidae. General Catalogue of the Hemiptera. Northampton, Smith College, 581p.

1943. Membracidae of Guatemala. Ann. Ent. Soc. Amer. 36: 455-482. 
GERMAR, E.F. 1821. Bemerkungen uber einige Gattungen der Cicadarien. Mag. Ent. 4: 1-106. 1835. Species Membracidum Musae E. F. Germari. Rev. Ent. Silberm. 3: $223-262$.

GodING, F.W. 1928. Membracidae of South America and Antilles, III. Subfamily Membracinae. Jour. N.Y. Ent. Soc. 36: 201-234.

- 1929. New Membracidae IX. Jour N.Y. Ent. Soc. 37: 171-174.

MCKameY, S.H. \& L.L. DeiTZ. 1991. Nomenclatural changes in the treehopper tribes Hoplophorionini, Smiliini, and Talipedini (Homoptera:Membracidae). Proc. Ent. Soc. Wash. 93 (1): 193-196.

METCALF, Z.P. \& V. WADE. 1965. General Catalogue of the Homoptera. Raleigh, North Carolina State University, 1552p.

SAKAKIBARA, A.M. \& A.J. CREÃo-DuARTE. 1996. Microschema Stål, gen. reval. and a correction in the labelling of the type specimen of Hoplophora straminicolor Stål, 1862 (Homoptera, Membracidae). Revta bras. Zool. 13 (4): 995-999.

STÅL, C. 1862. Bidrag till Rio-Janeiro tracktens Hemipter-fauna. Ofvers. af Svenska Vetens. Akad. Forh. 3 (6): 1-75. $1-130$.

WALKER, F. 1851. List of the specimens of homopterous insects in the collection of the British Museum, Part II. London, Edward Newman, 307p.

- 1858. Homoptera. Insecta Saundersiana: or characters of undescribed insects in the collection of William Wilson Saunders, Esq. $117 \mathrm{p}$.

. 1866. Analecta Hemipterologica. Baliner Ent. Zeit. 10: 381-394.

Recebido em 21.VI.1996; aceito em 20.XII.1996. 